\title{
Contribution of ocular B-mode and triplex Doppler in the evaluation of 10 Poodle dogs with cataracts
}

\author{
[Contribuição diagnóstica da ultrassonografia ocular e Doppler Triplex na avaliação de \\ 10 cães Poodle com catarata]
}

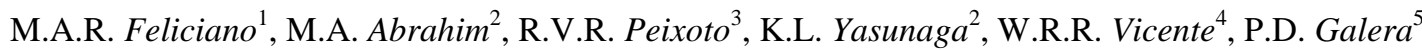 \\ ${ }^{1}$ Pós-Doutorando - UNESP-Jaboticabal - Jaboticabal, SP \\ ${ }^{2}$ Médica veterinária - Universidade de Brasília - Brasília, DF \\ ${ }^{3}$ Aluno de pós-graduação - Universidade de Brasília - Brasília, DF \\ ${ }^{4}$ UNESP-Jaboticabal - Jaboticabal, SP \\ ${ }^{5}$ Universidade de Brasília - Brasília, DFq
}

\begin{abstract}
The findings of b-mode and especially triplex Doppler ocular ultrasound in the evaluation of 10 Poodle dogs with cataracts, which bring a contribution not yet reported in veterinary medicine, were reported. Ten Poodle dogs of varied ages and presenting cataracts were used. All animals were evaluated for ophthalmic and ultrasound examination. The ultrasound examination allowed the evaluation of the sonographic anatomy of the eye and measurement of the axial thickness of the lens (ATL). Using the Doppler mode, the blood flow of the ophthalmic artery and its vascular indexes, systolic velocity (SV), resistive index (RI) and pulsatility index (PI) were measured. Values found for ATL were 5.89 \pm 1.05 for the right eye (OD) and $6.07 \pm 1.32$ for the left eye (OS). Values found using Doppler evaluation were SV OD: 26.54 \pm 7.05 and SV OS: 29.21 \pm 11.18 ; PI OD: $1.89 \pm 0.61$ and PI OS: $1.7 \pm 0.35$; RI OD: $0.76 \pm 0.1$ and RI OS: $0.72 \pm 0.09$ (OS). It was concluded that triplex Doppler was important for the determination of vascular indexes of the ophthalmic artery, which can be used for monitoring animals with hemodynamic alterations of the eyes and monitoring the therapy of ocular diseases.
\end{abstract}

Keywords: dog, ocular ultrasound, triplex Doppler, cataract

\section{RESUMO}

Descreveram-se os achados da ultrassonografia ocular convencional e, principalmente, do modo Doppler Triplex na avaliação de 10 cães da raça Poodle com catarata, contribuindo com parâmetros ainda não relatados em medicina veterinária. Foram utilizados 10 cães de diferentes idades e da raça Poodle, apresentando graus variados de catarata. Os animais foram submetidos ao exame oftalmológico e ultrassonográfico. Por meio da ultrassonografia avaliaram-se a anatomia ultrassonográfica dos bulbos oculares e a espessura axial da lente (EAL). Por meio do modo Doppler verificaram-se o tipo de fluxo sanguíneo da artéria oftálmica e seus índices vasculares, a velocidade sistólica (VS), o índice de resistência (RI) e a pulsatividade (PI). Os valores de EAL para olho direito (OD) foi de 5,89 $\pm 1,05$ e para

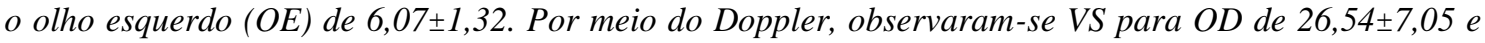

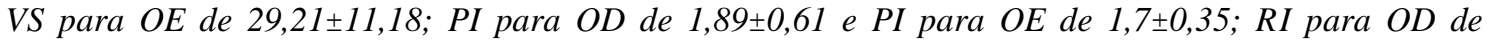

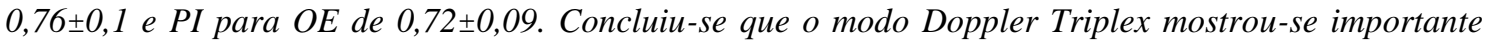
para determinação das medidas dos índices vasculares da artéria oftálmica, podendo ser utilizada para o acompanhamento de alterações hemodinâmicas nos olhos dos animais acometidos e no acompanhamento da terapia de doenças oculares.

Palavras-chave: cão, ultrassonografia ocular, tríplex Doppler, catarata

Recebido em 10 de outubro de 2011

Aceito em 12 de outubro de 2012

E-mail: dra.paulagalera@gmail.com 


\section{INTRODUCTION}

Diagnostic ocular ultrasound is a twodimensional imaging technique used to determine anatomical standards and pathological alterations, especially when ocular and intraocular opacities prevent the assessment of the posterior segment of the eye (GelattNicholson et al., 1999; Petite, 2009). Recently, color Doppler has allowed the determination of velocity patterns in the eye vasculature. According to Rankin (1999), the Doppler mode is a noninvasive technique used to investigate the retrobulbar circulation and the characteristics of the blood flow.

This diagnostic method is used to evaluate the eye's blood flow and its characteristics and vascular indexes such as systolic velocity of the vessels of the eye. Images obtained from the blood vessels by means of Doppler ultrasound are important for the study of ocular vessels, including ophthalmic artery, anterior ciliary artery, long and short ciliary arteries and primary retinal artery. Among the evaluations, the vascular resistive index (RI) and pulsatility index (PI) have been used to evaluate vascular resistance in canine glaucoma and also for therapeutic effects of systemic anti-hypertensive drugs (Novellas et al., 2007).

Gonçalves et al. (2008) reported that several ophthalmic diseases such as diabetic retinopathy, glaucoma and hypertension show significant alterations in the ocular vascular pattern. Ophthalmic changes which are related to hemodynamic diseases which can cause eye lesions which can many times lead to irreversible losses of vision have also been reported. The main alterations are tortuous retinal vessels, vitreous and retinal hemorrhage, retinal detachment and degeneration.

The evaluation of ocular vascularization can also provide information on neovascularization in cases of neoplasms and it is important for patient prognosis and choice of adequate therapy (Gonzalez et al., 2001). Cataract is the loss of transparency of the lens and has been described as one of the most common causes of loss of vision in dogs (Park et al., 2009). The presence of cataracts prevents an adequate evaluation of the vitreous and ocular ultrasound and can be an important tool for evaluating these structures (Gonzalez et al., 2001).

The aim of this study is to describe b-mode and triplex Doppler ocular ultrasound findings in the evaluation of 10 Poodle dogs with cataract. No data regarding triplex Doppler in dogs with cataracts can be found in the literature, thus, these findings can serve as parameters for future studies and can be used in veterinary ophthalmology practice.

\section{MATERIALS AND METHODS}

Ten Poodle dogs, patients of an Ophthalmology Department of a Veterinary Teaching Hospital, of various ages and diagnosed with different degrees of cataracts were evaluated in this prospective study. For the diagnosis of ocular disease and determination of cataract degree, animals were subjected to physical and ophthalmic examination. All data from this preliminary evaluation was archived with the animals' identification files.

The instillation of $0.5 \%$ proxymetacaine hydrochloride was used as topical anesthesia for the ultrasound examination. Conventional ocular ultrasound was performed with SONOSCAPE equipment and a $13 \mathrm{MHz}$ linear transducer. Bmode allowed the evaluation of anatomical characteristics and ocular echogenicity of dogs with cataracts through the determination of ocular lesions and biometry of the lens (axial thickness of the lens).

Triplex Doppler mode was performed using the same ultrasound equipment. This diagnostic technique allowed the evaluation of vascular characteristics of the eyes of animals with cataract, such as type of flow of the ophthalmic artery (normal or turbulent) and the determination of vascular indexes of this vessel, namely systolic velocity (SV), vascular resistance index (RI) and pulsatility index (PI).

\section{RESULTS AND DISCUSSION}

The main conventional ultrasound findings in this prospective study with dogs with cataracts were: opacification of the anterior capsule of the lens, echoes within the aqueous humor and lens, vitreous humor exhibiting mixed echogenicity, discontinuity of the retina, 
increased echogenicity and surface irregularity of the bottom of the eye, thinning of the ciliary body (temporal region) (Figure 1).

The results found through ocular conventional ultrasound in dogs with cataracts are in agreement with findings reported by several other authors in veterinary medicine (Gonzalez et al., 2001; Squarzoni et al., 2007; Martins et al., 2010). Conventional ultrasound examination of the eye in animals with cataract is an important step in preoperative evaluation of patients that will be subjected to cataract removal (Martins et al., 2010).

The axial thicknesses of the lens measured by conventional ocular ultrasound biometry are expressed in Table 1.

The values found in the present study for lens thickness measured by ocular ultrasound biometry in dogs were lower than those found in other studies reported by Williams (2004). According to the author, the pathogenesis of cataracts can influence the results, such as when osmotic effects promote increase in water levels in the lens and result in edema. It is suggested that this statement from the literature can explain differences observed between the values in our study and those in other reports.

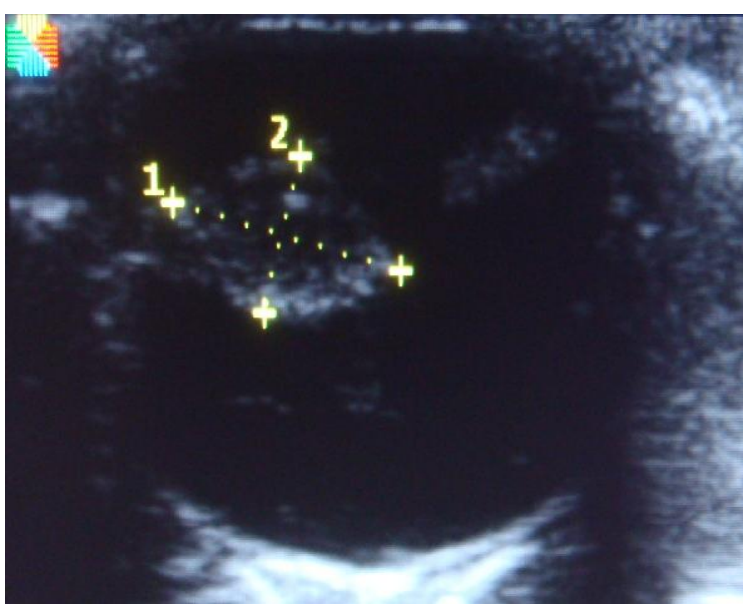

Figure 1. Sonographic images of the eye of a Poodle dog with cataracts. Biometric lens and presence of crystalline dislocation.
Table 1. Mean axial thickness of the lens (ATL) values for dogs with cataract from this study and dogs with various pathologies, according to Williams (2004)

\begin{tabular}{lc}
\hline Types of Lens & Values $(\mathrm{mm})$ \\
\hline ATL right eye $^{1}$ & $5.89 \pm 1.05$ \\
ATL left eye $^{1}$ & $6.07 \pm 1.32$ \\
Congenital cataracts $^{2}$ & $6.2 \pm 0.7$ \\
Immature cataracts $^{2}$ & $6.4 \pm 0.8$ \\
Mature cataracts $^{2}$ & $7.4 \pm 0.9$ \\
Diabetogenic cataracts $^{2}$ & $8.4 \pm 0.9$ \\
\hline
\end{tabular}

${ }^{1}$ values measured in the present study; ${ }^{2}$ values reported by Williams (2004)

The color Doppler evaluation of the ophthalmic artery showed only one animal with laminar flow and all the other exhibited turbulent flow (Figure 2). The alterations found in the blood flow evaluated by color Doppler suggest the presence of malignant lesions, according to Feliciano et al. (2012). Therefore, cataract is considered a disease that can cause important alterations on ocular blood flow.

Values for systolic velocity, pulsatility index and resistive index of the ophthalmic artery evaluated by triplex Doppler in dogs with cataract and in healthy animals (according to Novellas et al., 2007) are exhibited in Table 2.

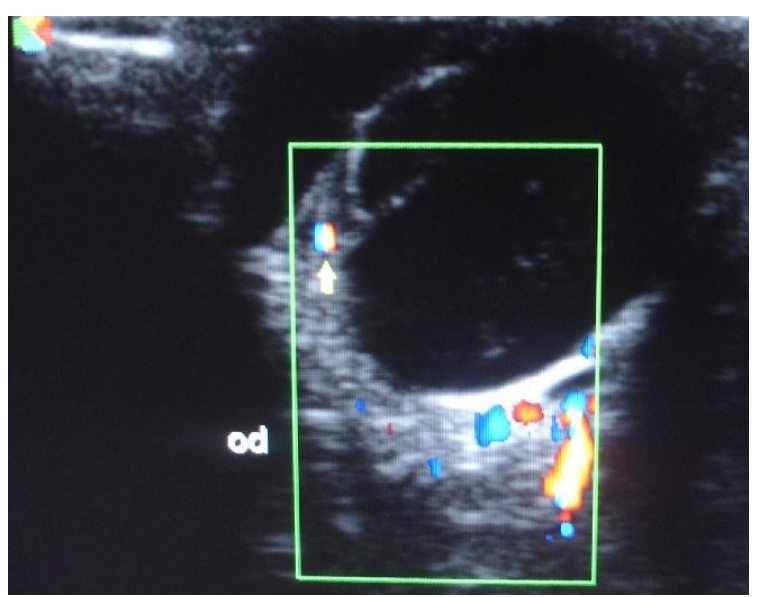

Figure 2. Image in color Doppler mode of the eye of a Poodle dog with cataracts and the presence of ocular vascularization and neovascularization in the lens region. 
Table 2. Mean values for vascular indexes of the ophthalmic artery of dogs with cataracts in this study and healthy dogs according to Novellas et al. (2007)

\begin{tabular}{lcc}
\hline Vascular indexes & Mean Values & Values for healthy dogs ${ }^{1}$ \\
\hline Systolic velocity $(\mathrm{cm} / \mathrm{s})$ - right eye & $26.54 \pm 7.05$ & $----{ }^{*}$ \\
Systolic velocity (cm/s) - left eye & $29.21 \pm 11.18$ & -- - $^{*}$ \\
Pulsatility index - right eye & $1.89 \pm 0.61$ & $1.15 \pm 0.21$ \\
Pulsatility index - left eye & $1.7 \pm 0.35$ & $1.15 \pm 0.21$ \\
Resistive index - right eye & $0.76 \pm 0.1$ & $0.63 \pm 0.06$ \\
Resistive index - left eye & $0.72 \pm 0.09$ & $0.63 \pm 0.06$ \\
\hline
\end{tabular}

${ }^{\mathrm{T}}$ Novellas et al. (2007); *Values not cited in veterinary literature

Note that PI and RI values in animals with cataract were higher than those reported for healthy animals by Novellas et al. (2007). According to those authors, these values can increase in cases of hemodynamic alterations caused by diseases such as hypertension.

Lee et al. (2002) reported that Doppler mode can be useful to determine vascular indexes in dogs during the investigation of pathophysiological processes of the eye or vascular alterations. Rankin (1999) reported an increase of resistive indexes of blood flow in animals with glaucoma through Doppler evaluation. According to the author, these changes can be correlated to the severity of the disease, asymmetry of blood flow in the affected area, intra ocular pressure and vasospasm, which can affect the velocity of local blood flow. Considering the literature data and the findings of the present study, we can affirm that dogs with cataract possibly undergo changes in the hemodynamic conditions of ocular vasculature, which result in increased pulsatility and resistive indexes.

Gonçalves et al. (2008) reported mean resistive index values of 0.4175 for the right eye and 0.4015 for the left eye on the ophthalmic artery of healthy cats. Note that these values are lower than those found for healthy dogs and dogs with cataracts.

There are no studies which correlate systolic velocity of the ophthalmic artery and the changes that occur in healthy or diseased dogs. For healthy cats, systolic velocity was $41.30 \mathrm{~cm} / \mathrm{s}$ for the right eye and $42.75 \mathrm{~cm} / \mathrm{s}$ for the left eye (Gonçalves et al., 2008). It is interesting to note that the values reported by those authors were higher than the values found in this study. The evaluation of blood flow velocity can be compromised by stress and this mechanism is much more active in cats than in dogs.

The results obtained using Doppler mode reaffirm that this method can be used for monitoring efficacy of therapy of eye diseases such as ocular hypertension and neoplasms. This statement corroborates reports by Choi et al. (2011), who found that some anti-glaucoma drugs can have effects on the ophthalmic artery blood flow. Those authors also claim that these changes can be beneficial or harmful to the eyes and new studies are being conducted to determine this effect more precisely.

\section{CONCLUSION}

It was concluded that ocular ultrasound in an essential diagnostic tool when performing an ophthalmic evaluation of dogs with cataracts and is useful when opacification of anterior structures prevent a direct examination of the eye. This technique can also determine which surgical procedure will take part in the treatment of dogs with cataracts. Triplex Doppler mode in animals with cataracts is a new diagnostic method for the study of this disease in dogs. This technique proved to be important to determine vascular indexes of the ophthalmic artery and, combined with the Power Doppler technique, can be used to monitor hemodynamic alterations of the eyes of affected animals and also monitor therapeutic effects.

\section{ACKNOWLEDGEMENTS}

The authors thank $\mathrm{CNPq}$ for the scientific initiation scholarship. 


\section{REFERENCES}

CHOI, H.; LEE, Y.; YEON, S. et al. Effects of anti-glaucoma drugs on resistive index of the medial long posterior ciliary artery using color Doppler imaging in Beagle dogs. J. Vet. Sci., v.12, p.99-101, 2011.

FELICIANO, M.A.R.; VICENTE, W.R.R.; SILVA, M.A.M. Conventional and Doppler ultrasound for the differentiation of benign and malignant canine mammary tumours. JSAP, v.53, p.332-7, 2012.

GELATT-NICHOLSON, K.J.; GELATT, K.N.; MACKAY, E. et al. Doppler imaging of the ophthalmic vasculature of the normal dog: blood velocity measurements and reproducibility. Vet. Ophthal., v.2, p.87-96, 1999.

GONÇALVES, G.F.; PIPPI, N.L.; LEME, M.C. et al. Correlação entre a pressão arterial média e o fluxo sangüíneo na artéria oftalmica externa em gatos (felis catus linnaeus, 1758). Braz. J. Vet. Res. Anim. Sci., v.45, p.57-66, 2008.

GONZALEZ, E.M.; RODRIGUEZ, A.; GARCIA, I. Review of ocular ultrasonography. Vet. Radiol. Ultrasound, v.42, p.485-495, 2001.

LEE, H.; CHANG, D.; LEE, Y. et al. Use of color doppler imaging for determining the resistive index of the medial long posterior ciliary artery in clinically normal conscious dogs. AJVR., v.63, p.211-214, 2002.
MARTINS, B.C.; RODRIGUES JR, E.F.; SOUZA, A.L.G. et al. A and B mode ultrasonography in preoperative evaluation of lens and posterior segment of dogs eyes with cataract. Pesq. Vet. Bras., v.30, p.121-126, 2010.

NOVELLAS, R.; ESPADA, Y.; GOPEGUI, R.R. Doppler ultrasonographic estimation of renal and ocular resistive and pulsatility indices in normal dogs and cats. Vet. Radiol. Ultrasound, v.48, p.69-73, 2007.

PARK, S.A.; YI, N.Y.; JEONG, M.B. et al. Clinical manifestations of cataracts in small breed dogs. Vet. Ophthal., v.12, p.205-210, 2009.

PETITE, A. Ocular Ultrasonography. In: BRITSH SAMAL ANIMAL VETERINARY ASSOCIATION, 2009, Birmingham. Proceedings..., Gloucester: British Small Animal Veterinary Association ,2009.

RANKIN, S.J. Color Doppler imaging of the retrobulbar circulation in glaucoma. Surv. Ophthal., v.43, p.176-182, 1999.

SQUARZONI, R.; MORALES, M.S.A.; SAFATLE, A.M.V. et al., Ultrasonographic evaluation of the eyes' posterior segment of diabetic and non-diabetic dogs with cataracts. Pesq. Vet. Bras., v.27, p.455-461, 2007.

WILLIAMS, D.L. Lens morphometry determined by B-mode ultrasonography of the normal and cataractous canine lens. Vet. Ophthal., v.7, p.91-95, 2004. 